\title{
Closed-Loop Feedback Flank Errors Correction of Topographic Modification of Helical Gears Based on Form Grinding
}

\author{
Huiliang Wang, Jubo Li, Yang Gao, and Jianjun Yang \\ School of Mechatronics Engineering, Henan University of Science and Technology, \\ Luoyang, Henan 471003, China \\ Correspondence should be addressed to Huiliang Wang; whl-ly@163.com
}

Received 30 December 2014; Revised 16 February 2015; Accepted 16 February 2015

Academic Editor: Ivan D. Rukhlenko

Copyright (C) 2015 Huiliang Wang et al. This is an open access article distributed under the Creative Commons Attribution License, which permits unrestricted use, distribution, and reproduction in any medium, provided the original work is properly cited.

To increase quality, reduce heavy-duty gear noise, and avoid edge contact in manufacturing helical gears, a closed-loop feedback correction method in topographic modification tooth flank is proposed based on the gear form grinding. Equations of grinding wheel profile and grinding wheel additional radial motion are derived according to tooth segmented profile modification and longitudinal modification. Combined with gear form grinding kinematics principles, the equations of motion for each axis of fiveaxis computer numerical control forming grinding machine are established. Such topographical modification is achieved in gear form grinding with on-machine measurement. Based on a sensitivity analysis of polynomial coefficients of axis motion and the topographic flank errors by on-machine measuring, the corrections are determined through an optimization process that targets minimization of the tooth flank errors. A numerical example of gear grinding, including on-machine measurement and closed-loop feedback correction completing process, is presented. The validity of this flank correction method is demonstrated for tooth flank errors that are reduced. The approach is useful to precision manufacturing of spiral bevel and hypoid gears, too.

\section{Introduction}

Helical gears play an important role in the aerospace, automobile, wind power, and other mechanical transmission devices. The precision and shape of the tooth surface directly affect the performance of the device. Machine errors, heat treatment distortions, variation of cutting forces, and other unpredictable factors reduce gear quality and cause unfavorable displacement of tooth contact and increased transmission errors, resulting in edge contact and highly concentrated stresses. In practice, gear form grinding can be a very effective means for eliminating tooth flank errors of heavy-duty or large-size gear. To meet the demand of these kinds of gears, a combination of profile and longitudinal crowning is applied on the tooth flank to increase the gear load capacity and reduce vibrations and noise of the gear drive. Nonetheless, no correction method based on-machine measurement has been proposed for flank topography, even though many authors cite related research based on bevel and cylindrical gears [15].

Within related research, Shih and Chen [6] proposed a free-form flank correction in helical gear grinding using a five-axis computer numerical control gear profile grinding machine, but the errors of the actual tooth surface are assessed using the gear measurement center not on-machine measurement. Fan et al. $[7,8]$ presented a method of higherorder tooth flank form error correction for face-milled spiral bevel and hypoid gears based on coordinate measurement machine. Yoshino and Ikeno [9] established a flank correction method for profile grinding bypass compensation of the wheel appearance and the position between the wheel and the gear to reduce transmission error. Litvin et al. $[10,11]$ changed the fixed gear ratio into modification ratio of the grinding wheel and the work gear, so as to achieve topological modification for reducing transmission error and noise. Kobayashi et al. $[12,13]$ calculated the angle of the grinding 
wheel installation and optimized contact line between the grinding wheel and lengthwise modification, in order to achieve the accuracy of the gear flank profile. Krenzer [14] proposed corrective machine setting method for face-milled hypoid gears. Zhang et al. [15] proposed a method of gear tooth surface modification through compensation of the grinding wheel profile and the relative position of the wheel and work gear, to improve the accuracy of the tooth surface. Lee et al. $[16,17]$ fabricated a modified cylindrical gear drive that can reproduce precisely the predesigned fourth-order polynomial function of transmission error. Gorla and Rosa [18] established a mathematical model for the ground surface in the process of a form grinding method with a plunging operation and researched the effect of the wheel setting angle on the ground surface. Artoni et al. [19] proposed a novel ease-off based compensation of tooth surface deviations for spiral bevel and hypoid gears to achieve a high level of accuracy of transmission properties. Simon [20] used a method for the determination of optimal tooth modifications in spiral bevel gears based on improved load distribution and reduced maximum tooth contact pressure and transmission errors. Kolivand and Kahraman [21] developed a load distribution model for hypoid gears using ease-off topography and shell theory to optimize the tooth profiles for desired contact patterns. However, although their methods for bevel gears or cycloidal gears provided a development of a flank correction, they did not propose closed-loop correction for topological modification flank on gear form grinding.

This work aims to establish a closed-loop feedback flank errors correction methodology based on the five-axis computer numerical control gear form grinding machine. First, we established a mathematical model of topological modified tooth flank. Subsequently, using on-machine measured topographic errors of tooth surfaces, we established a sensitivity analysis model. Next, we derive the corrections to the fiveaxis movement for reducing grinding errors. Then, we clearly explain the feasibility of the closed-loop feedback flank errors correction using a numerical example of a helical gear made by the gear grinding machine. Finally, experimental results will show that this method has application value in improving accuracy of the gear.

The outline of the remainder of the paper is as follows. In Section 2, a topological modified model of a helical gear based on the gear form grinding is developed. On-machine measurement method is the main subject of Section 3. In Section 4 flank errors correction model is established. A closed-loop correction process and numerical example are illustrated in Sections 5 and 6. Finally, some conclusions are drawn in Section 7.

\section{Topological Modified Tooth Flank on Form Grinding}

2.1. Axis Motion of Form Grinding Machine. At present, attempts to avoid edge contact of tooth surfaces caused by misalignment are achieved through profile and longitudinal crowning. We call this crowning "segmented topology modification" where tooth surfaces have been divided into

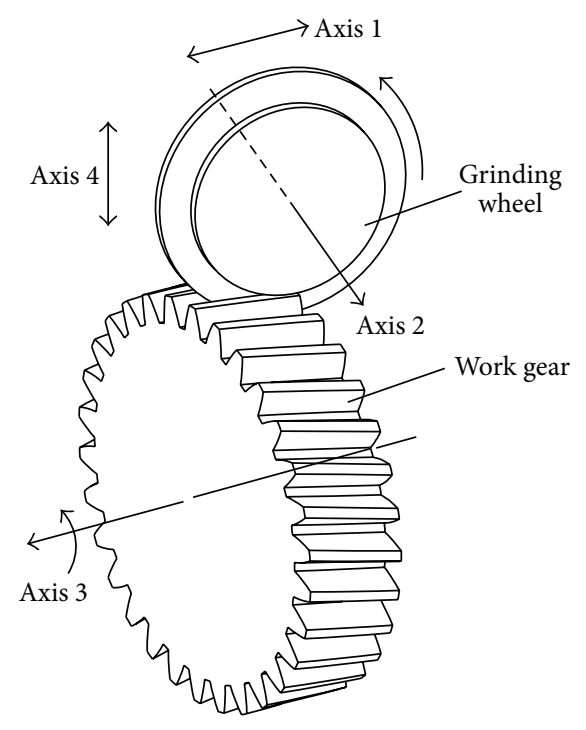

FIGURE 1: Schematic illustration of gear form grinding by a grinding wheel.

involute and crowned zones. A nonmodified zone is provided in the central area of gear tooth surfaces that will allow line contact if there are no installation errors. The other zones including the top, bottom, front, and back sides of tooth surfaces are crowned and improve bearing contact when installation errors occur. The authors propose application for the finishing process of a grinding wheel (Figure 1) that permits a topological modified tooth surface, avoids areas of severe contact stresses, reduces level of transmission errors, and lessens sensitivity to errors of alignment. The basic idea of the topological modification of tooth flank by the form grinding is application of modified wheel and the grinding path. The axis applied for form grinding is as follows.

(1) Axis one corresponds to the feed motion of the grinding wheel along the face width of the gear.

(2) Axis two is the rotation of the grinding wheel.

(3) Axis three is the rotation of the work gear.

(4) Axis four corresponds to the longitudinal crowning motion of the grinding wheel along radial direction of the gear.

2.2. Tooth Surface Topological Modification Zones. Segmented topological modification crowns the tooth surface in profile and longitudinal direction at the same time. Profile segment modification is achieved by modifying the grinding wheel, and longitudinal segment modification is completed by changing the grinding path of the wheel relatively to the gear. Figure 2 shows a 3D schematic view of the topological modified tooth flank, where $\Sigma_{1}$ is a theoretical involute tooth surface and $\Sigma_{2}$ is a topological modified tooth surface. $\Sigma_{2}$ includes nine desired zones of crowned gear tooth surface, where zone 1 is a nonmodified surface corresponding to the standard geometry of a grinding wheel and no modifications 


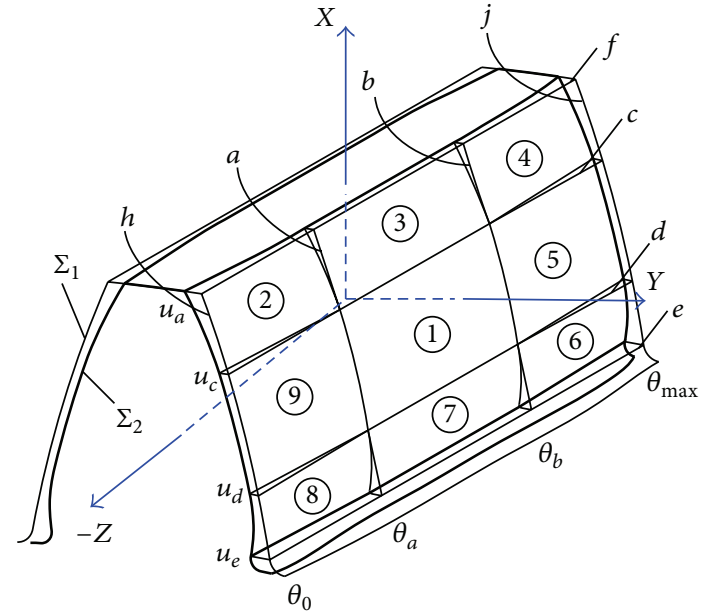

Figure 2: Topology of gear tooth flank surface. are provided in this zone; zones 2, 4, 6, and 8 are the areas of crowning in profile and longitudinal directions; zones 5 and 9 are the areas of crowning in longitudinal direction; zones 3 and 7 are the areas of crowning in profile direction. In Figure 2, $u_{e}, u_{d}, u_{c}$, and $u_{a}$ are involute parameters of boundary line $e, d, c$, and $f$ in profile crowning direction, and $\theta_{0}, \theta_{a}, \theta_{b}$, and $\theta_{\max }$ are the gear rotation angles of boundary line $h, a, b$, and $j$ in longitudinal direction. So we can change the surface parameters $u_{1}$ and $\theta_{1}$ to control crowning zone size.

Axial profile of the wheel spirals along the axis direction and does parabolic movement in the radial direction of the work gear at the same time. The formed track is thought of as the topological modification tooth surface, so the crossline equation of wheel axial profile and middle section of the work gear can be used to obtain the tooth flank equation as described by (1) in [22]. Consider

$$
\mathbf{r}_{1}=\left[\begin{array}{c}
r_{b} \cos \left(\sigma_{1}+u_{1}-\theta_{1}\right)+\left(r_{b} u_{1}-\Delta L\right) \sin \left(\sigma_{1}+u_{1}-\theta_{1}\right)-a_{x} \cos \theta_{1} \\
r_{b} \sin \left(\sigma_{1}+u_{1}-\theta_{1}\right)-\left(r_{b} u_{1}-\Delta L\right) \cos \left(\sigma_{1}+u_{1}-\theta_{1}\right)+a_{x} \sin \theta_{1} \\
p_{1} \theta_{1} \\
1
\end{array}\right],
$$

where $\left(u_{1}, \theta_{1}\right)$ are surface parameters, $r_{b}$ is base radius, $\sigma_{1}$ is tooth space half angle, $\Delta L$ is profile crowning value, $a_{x}$ is longitudinal motion value, and $p_{1}$ is helix parameters, respectively.

Topological crowning includes profile modification and longitudinal modification. The former uses wheel crowning to accomplish process; the latter changes the relative moving trajectory of the wheel and the gear. The applied profile crowning equation and wheel feeding motion are shown in Table 1. The modified topology of the gear tooth surface shown in Figure 2 can be obtained by application of (1). Crowning coefficients in profile and longitudinal modification are applied as follows.

(1) On the top side, zones 2, 3, and 4 will be provided by profile crowning with a coefficient $a_{m p(c f)}$ starting at $u_{c}$.

(2) On the bottom side, zones 6,7 , and 8 will be provided by profile crowning with a coefficient $a_{m p(d e)}$ ending at $u_{d}$.

(3) On the front side, zones 4, 5, and 6 will be provided by longitudinal crowning with a coefficient $a_{m l(b j)}$ starting at $\theta_{b}$.

(4) On the back side, zones 2, 9, and 8 will be provided by longitudinal crowning with a coefficient $a_{m l(h a)}$ ending at $\theta_{a}$.

2.3. Mathematical Model for Form Grinding. Compared with the traditional method for generating grinding, form grinding method requires not only wheel modification of high precision, but also accuracy position relative to the work piece and the grinding wheel in radial and tangential direction. Gear form grinding is arranged based on the universal CNC gear form grinding machine, which has five digital servo closed-loop controlled axes: three rectilinear motions $(X, Y, Z)$ and two rotational motions $(A, C)$ (see Figure 3 ). $\mathrm{SP}_{1}$ and $\mathrm{SP}_{2}$ are spindles of the wheel and diamond wheel, respectively.

Coordinate systems $S_{t}\left(x_{t}, y_{t}, z_{t}\right)$ and $S_{1}\left(x_{1}, y_{1}, z_{1}\right)$, whose relative positions are described by the auxiliary coordinate systems from $S_{a}\left(x_{a}, y_{a}, z_{a}\right)$ to $S_{c}\left(x_{c}, y_{c}, z_{c}\right)$, are rigidly connected to the grinding wheel and work gear, respectively. Here, $\varphi_{c}$ is the rotation angle of the work gear, and $\varphi_{a}$ is the swivel angle of the grinding wheel. $C_{x}$ is the radial motion for feeding the wheel down to tooth depth along the vertical stroke motion $C_{z}$. This machine is equipped with NC dressing devices which include motions of $C_{y}$ and $C_{z}$. Parameter $k_{1}$ is a machine installation coefficient that depends on the grinding machine and is measured immediately after machine installation.

Evidently, the motions of the five axes are also functions of the work gear rotation angle $\varphi_{a}\left(\varphi_{a}=\varphi_{1}\right)$. So they can be approximated in terms of the work gear rotation angle $\varphi_{a}$ by n-degree Maclaurin polynomials:

$$
\begin{aligned}
f_{i}\left(\varphi_{1}\right)= & f_{i}(0)+f_{i}^{\prime}(0) \cdot \varphi_{1}+\frac{f_{i}^{\prime \prime}(0) \cdot \varphi_{1}^{2}}{2 !} \\
& +\cdots+\frac{f_{i}^{(n)}(0) \cdot \varphi_{1}^{n}}{n !}+R_{i}^{(n)}\left(\varphi_{1}\right) \quad(i=x, y, z, a, c),
\end{aligned}
$$



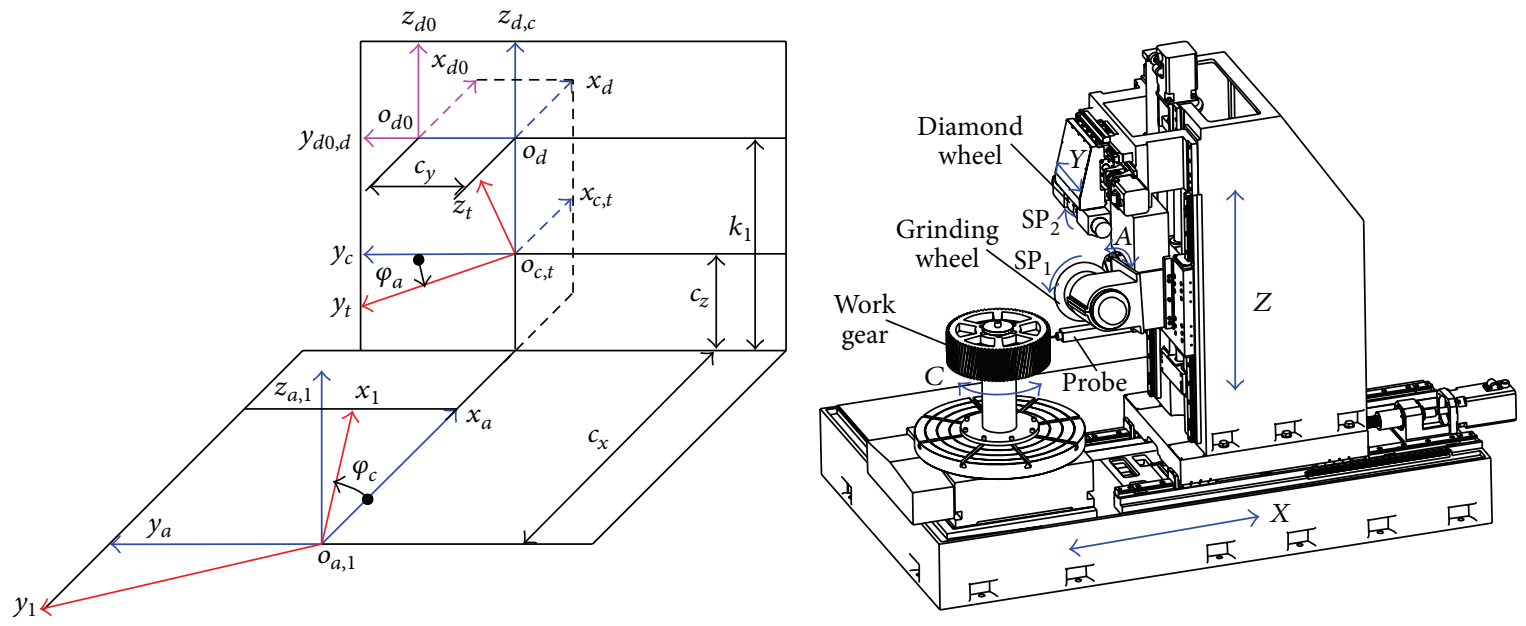

FIGURE 3: Model of gear form grinding machine with on-machine measurement.

TABLE 1: Applied relations of motion at zones during gear form grinding.

\begin{tabular}{lcc}
\hline Zone & Profile crowning equation & Wheel feed equation \\
\hline 1 & $\Delta L=0$ & $a_{x}=0$ \\
2 & $\Delta L=a_{m p(c f)} r_{b}^{2}\left(u_{1}-u_{c}\right)^{2}$ & $a_{x}=a_{m l(h a)} p_{1}^{2}\left(\theta_{a}-\theta_{1}\right)^{2}$ \\
3 & $\Delta L=a_{m p(c f)} r_{b}^{2}\left(u_{1}-u_{c}\right)^{2}$ & $a_{x}=0$ \\
4 & $\Delta L=a_{m p(c f)} r_{b}^{2}\left(u_{1}-u_{c}\right)^{2}$ & $a_{x}=a_{m l(b j)} p_{1}^{2}\left(\theta_{1}-\theta_{b}\right)^{2}$ \\
5 & $\Delta L=0$ & $a_{x}=a_{m l(b j)} p_{1}^{2}\left(\theta_{1}-\theta_{b}\right)^{2}$ \\
6 & $\Delta L=a_{m p(d e)} r_{b}^{2}\left(u_{d}-u_{1}\right)^{2}$ & $a_{x}=a_{m l(b j)} p_{1}^{2}\left(\theta_{1}-\theta_{b}\right)^{2}$ \\
7 & $\Delta L=a_{m p(d e)} r_{b}^{2}\left(u_{d}-u_{1}\right)^{2}$ & $a_{x}=0$ \\
8 & $\Delta L=a_{m p(d e)} r_{b}^{2}\left(u_{d}-u_{1}\right)^{2}$ & $a_{x}=a_{m l(h a)} p_{1}^{2}\left(\theta_{a}-\theta_{1}\right)^{2}$ \\
9 & $\Delta L=0$ & $a_{x}=a_{m l(h a)} p_{1}^{2}\left(\theta_{a}-\theta_{1}\right)^{2}$ \\
\hline
\end{tabular}

where $i$ indicates each axis of gear form grinding machine and $R_{i}^{(n)}\left(\varphi_{1}\right)$ is the remainder of the Maclaurin series. So we define the machine axis motion in a dynamic manner by polynomials as

$$
\begin{aligned}
C_{x}\left(\varphi_{1}\right)= & C_{x 0}+C_{x 1} \varphi_{1}+C_{x 2} \varphi_{1}^{2}+C_{x 3} \varphi_{1}^{3}+C_{x 4} \varphi_{1}^{4} \\
& +C_{x 5} \varphi_{1}^{5}+C_{x 6} \varphi_{1}^{6} \\
C_{y}\left(\varphi_{1}\right)= & C_{y 0}+C_{y 1} \varphi_{1}+C_{y 2} \varphi_{1}^{2}+C_{y 3} \varphi_{1}^{3}+C_{y 4} \varphi_{1}^{4} \\
& +C_{y 5} \varphi_{1}^{5}+C_{y 6} \varphi_{1}^{6} \\
C_{z}\left(\varphi_{1}\right)= & C_{z 0}+C_{z 1} \varphi_{1}+C_{z 2} \varphi_{1}^{2}+C_{z 3} \varphi_{1}^{3}+C_{z 4} \varphi_{1}^{4} \\
& +C_{z 5} \varphi_{1}^{5}+C_{z 6} \varphi_{1}^{6} \\
\varphi_{a}\left(\varphi_{1}\right)= & \varphi_{a 0}+\varphi_{a 1} \varphi_{1}+\varphi_{a 2} \varphi_{1}^{2}+\varphi_{a 3} \varphi_{1}^{3}+\varphi_{a 4} \varphi_{1}^{4} \\
& +\varphi_{a 5} \varphi_{1}^{5}+\varphi_{a 6} \varphi_{1}^{6} \\
& +\varphi_{c 5} \varphi_{1}^{5}+\varphi_{c 6} \varphi_{1}^{6} \\
\varphi_{c}\left(\varphi_{1}\right)= & +\varphi_{c 1} \varphi_{1}+\varphi_{c 2} \varphi_{1}^{2}+\varphi_{c 3} \varphi_{1}^{3}+\varphi_{c 4} \varphi_{1}^{4} \\
&
\end{aligned}
$$

where $\varphi_{1}$ is the gear rotation angle value. Each machine axis motion is represented by a moving element whose motion is represented as a polynomial equation in terms of gear rotation angle. The first terms in (3) represent traditional basic machine axis motions; the other terms represent kinematic flank correction axis motions. There are a total of $35(5 \times$ 7) coefficients in (3). Since the gear rotation angle is the parameter of the traditional machine motions, the tooth flank form geometry can be represented by a position vector as follows:

$$
\mathbf{r}_{1}=\mathbf{r}_{1}\left(u_{1}, \theta_{1}, \varphi_{1}\right)
$$

where $\left(u_{1}, \theta_{1}\right)$ are tooth surface parameters and $\varphi_{1}$ is the parameter of form grinding motion.

According to differential geometry, the unit normal vector to the surface locus may then be represented in coordinate system $S_{1}$ by

$$
\begin{aligned}
\mathbf{n}_{1} & \left(u_{1}, \theta_{1}, \varphi_{1}\right) \\
& =\frac{\left(\partial \mathbf{r}_{1}\left(u_{1}, \theta_{1}, \varphi_{1}\right) / \partial u_{1}\right) \times\left(\partial \mathbf{r}_{1}\left(u_{1}, \theta_{1}, \varphi_{1}\right) / \partial \theta_{1}\right)}{\left|\left(\partial \mathbf{r}_{1}\left(u_{1}, \theta_{1}, \varphi_{1}\right) / \partial u_{1}\right) \times\left(\partial \mathbf{r}_{1}\left(u_{1}, \theta_{1}, \varphi_{1}\right) / \partial \theta_{1}\right)\right|}
\end{aligned}
$$

The equation of meshing relating the three parameters $\left(u_{1}, \theta_{1}, \varphi_{1}\right)$ is

$$
\begin{aligned}
f_{1} & =\mathbf{n}_{1}\left(u_{1}, \theta_{1}, \varphi_{1}\right) \cdot \mathbf{v}_{1}^{(t 1)}\left(u_{1}, \theta_{1}, \varphi_{1}\right) \\
& =\mathbf{n}_{1}\left(u_{1}, \theta_{1}, \varphi_{1}\right) \cdot\left(\dot{\varphi}_{1} \frac{\partial \mathbf{r}_{1}\left(u_{1}, \theta_{1}, \varphi_{1}\right)}{\partial \varphi_{1}}\right)=0,
\end{aligned}
$$

where $v_{1}^{(t 1)}$ is the relative velocity between the grinding wheel and the work gear in coordinate system $S_{1}$ as the work gear is machining.

\section{On-Machine Measurement of Tooth Surface}

Using (4) to (6), the theoretical tooth surface geometry can be numerically represented by the coordinates of a group of 


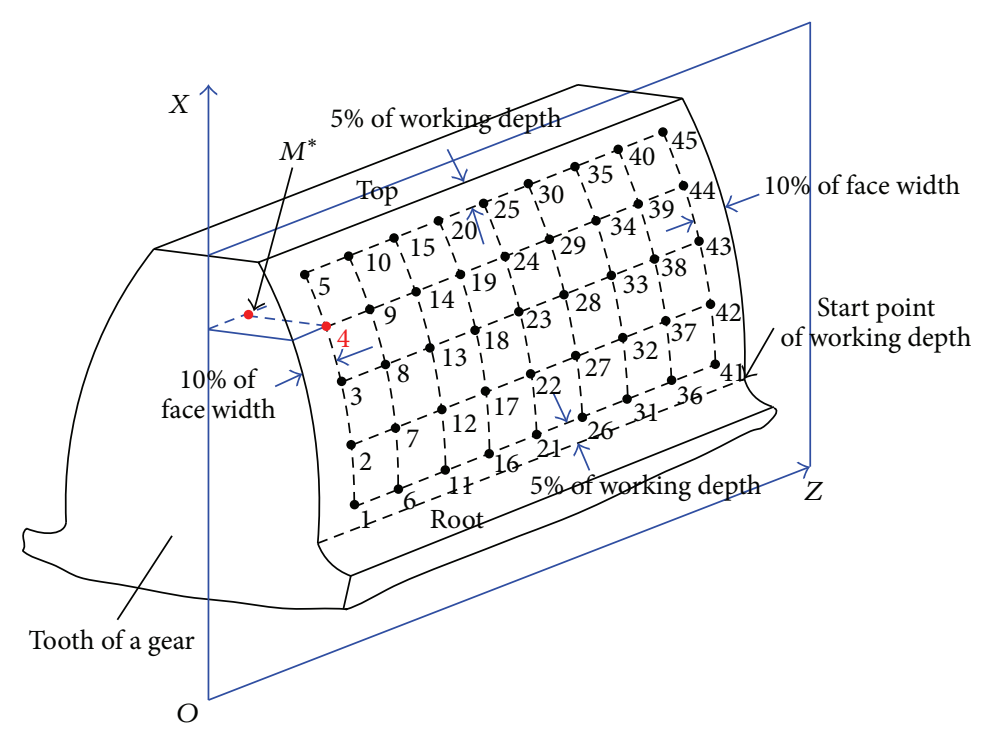

FIGURE 4: Definition of a tooth flank grid.

surface points defined in Figure 4. A grid of 5 lines and 9 columns is defined in the $X-Z$ axial plane of the work gear.

The plane coordinate system $X O Z$ is an axis of rotation projection section of the tooth surface, where $O$ is center point of base circle and $M^{*}$ is a point in the projection surface at any measured point in the tooth surface. Given a point by $\left(x^{*}, z^{*}\right)$ the following system of nonlinear equations can be used to solve for the surface parameters:

$$
\begin{gathered}
\sqrt{x_{i}^{2}+y_{i}^{2}}=x^{*} \\
z_{i}=z^{*} \\
f_{1}\left(u_{1}, \theta_{1}, \varphi_{1}\right)=0,
\end{gathered}
$$

where the coordinates $\left(x_{i}, y_{i}, z_{i}\right)$ are three coordinate components of tooth surface position vector $\mathbf{r}_{1}^{(i)}, i=1,2, \ldots, 45$. Solving nonlinear equations to get the tooth surface parameters $\left(u_{1}, \theta_{1}\right)$ for each measured point, which substitute into (3), can get the theoretical coordinates $\left(x_{1}^{(i)}, y_{1}^{(i)}, z_{1}^{(i)}\right)$ and the unit normal vector of tooth surface measured point as

$$
\begin{aligned}
& \mathbf{r}_{1}^{(i)}=\left[\begin{array}{lll}
x_{1}^{(i)} & y_{1}^{(i)} & z_{1}^{(i)}
\end{array}\right]^{T} \\
& \mathbf{n}_{1}^{(i)}=\left[\begin{array}{lll}
n_{1 x}^{(i)} & n_{1 y}^{(i)} & n_{1 z}^{(i)}
\end{array}\right]^{T} \\
& (i=1,2, \ldots, 2 * 45) .
\end{aligned}
$$

Taking into account the difficulty in heavy-duty or largesize gear handing, an on-machine measuring device is usually integrated into the wheel head and provides gear precision evaluation immediately. The gear form grinding machines involve three processes, gear grinding, wheel dressing, and gear measuring, so they must be equipped with enough axes to satisfy the demands of these three processes, respectively. Figure 5 shows the configuration of measuring the gear using on-machine measurement. Using the probe, the tooth surfaces are measured according to the given grid. The measured tooth flank form on-machine measuring device is obtained and numerically represented as

$$
\mathbf{r}_{m}^{(i)}=\left[\begin{array}{lll}
x_{m}^{(i)} & y_{m}^{(i)} & z_{m}^{(i)}
\end{array}\right]^{T} \quad(i=1,2, \ldots, 2 * 45) .
$$

The deviation between the nominal data of theoretical tooth surfaces and the measured tooth surfaces for each point of grid can be obtained by equation as follows:

$$
\delta^{(i)}=\left(\mathbf{r}_{m}^{(i)}-\mathbf{r}_{1}^{(i)}\right) \cdot \mathbf{n}_{1}^{(i)} \quad(i=1,2, \ldots, 2 * 45) .
$$

Equation (10) can be visually represented by error surfaces. Using a linear regression technique like the least squares method, the error surfaces of right tooth and left tooth can be represented by polynomials of two variables as

$$
\begin{aligned}
& \delta_{1}=a_{1} X+a_{2} Z+a_{3} X^{2}+a_{4} X Z+a_{5} Z^{2}+\cdots+a_{27} Z^{6} \\
& \delta_{2}=a_{1} X+a_{2} Z+a_{3} X^{2}+a_{4} X Z+a_{5} Z^{2}+\cdots+a_{27} Z^{6}
\end{aligned}
$$

where $\delta_{1}$ and $\delta_{2}$ are errors of right and left side tooth surfaces, respectively. Coordinates $X$ and $Z$ correspond to the tooth profile and longitudinal directions, respectively.

\section{Flank Errors Correction Method for Gear Form Grinding Machine}

In gear design, especially for heavy-duty or large-size gears, loaded tooth contact analysis is used to modify the tooth flank topographically in order to improve bearing contact and reduce level of loaded transmission errors. In gear manufacturing, the tooth flank deviations are composed of the profile and helix deviations which also cause topographic errors. To increase flank modification flexibility in a way that satisfies the design demands of heavy-duty or large-size gears on form grinding machine, we propose a closed-loop 


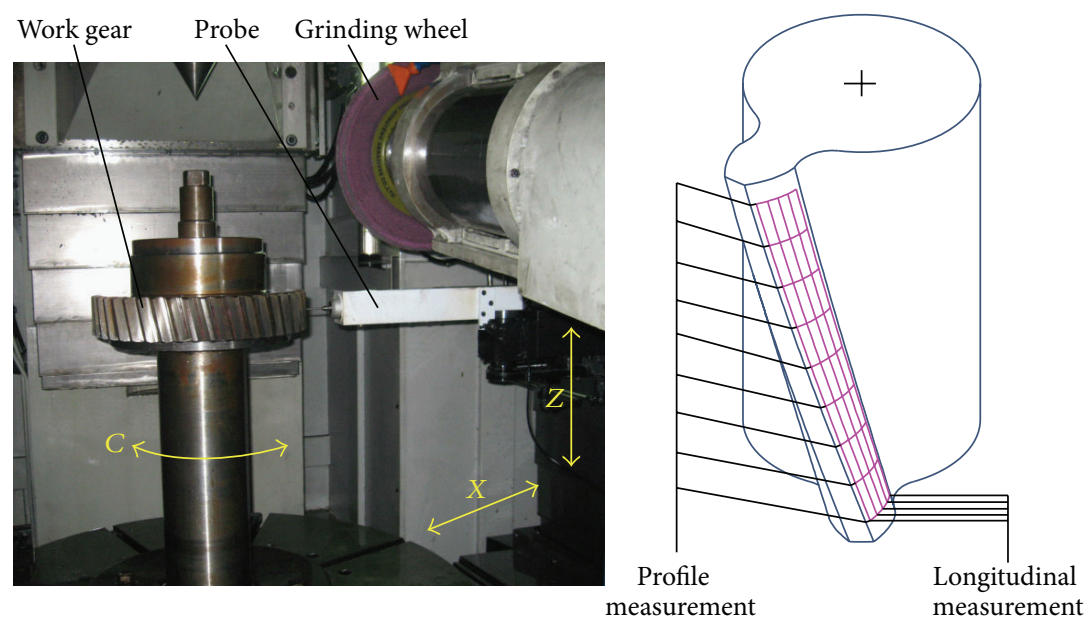

FIgURE 5: Tooth flank form on-machine measurement.

feedback flank errors correction method similar to that used in the manufacturing of cycloidal gears, which has become well developed over the last decade. In order to understand the response of tooth flank form geometry to the change of each motion coefficient in (2), we use the polynomial coefficients of the machine motion as variables. So the tooth surface of (4), (5), and (6) may be represented as

$$
\begin{array}{r}
\mathbf{r}_{1}=\mathbf{r}_{1}\left(u_{1}, \theta_{1}, \varphi_{1}, \xi_{j}\right) \\
\mathbf{n}_{1}=\mathbf{n}_{1}\left(u_{1}, \theta_{1}, \varphi_{1}, \xi_{j}\right) \\
f_{1}\left(u_{1}, \theta_{1}, \varphi_{1}, \xi_{j}\right)=0 \\
j=1,2, \ldots, 35,
\end{array}
$$

where $\xi_{j}$ generally designates the 35 universal motion coefficients in (3). According to differential geometry, the surface variation vector is represented by

$$
\begin{aligned}
\delta \mathbf{r}_{1}= & \frac{\partial \mathbf{r}_{1}\left(u_{1}, \theta_{1}, \varphi_{1}, \xi_{j}\right)}{\partial u_{1}} \delta u_{1}+\frac{\partial \mathbf{r}_{1}\left(u_{1}, \theta_{1}, \varphi_{1}, \xi_{j}\right)}{\partial \theta_{1}} \delta \theta_{1} \\
& +\sum_{j=1}^{q} \frac{\partial \mathbf{r}_{1}\left(u_{1}, \theta_{1}, \varphi_{1}, \xi_{j}\right)}{\partial \xi_{j}} \delta \xi_{j} .
\end{aligned}
$$

Because vectors $\partial \mathbf{r}_{1} / \partial u_{1}$ and $\partial \mathbf{r}_{1} / \partial \theta_{1}$ are both perpendicular to the surface normal $\mathbf{n}_{1}$ and inner product is zero, respectively, taking the inner product of both sides of the above equation with the surface normal gives the following simplified normal surface variation:

$$
\begin{aligned}
\delta \mathbf{r}_{1} \cdot \mathbf{n}_{1} & =\left(\frac{\partial \mathbf{r}_{1}}{\partial u_{1}} \delta u_{1}+\frac{\partial \mathbf{r}_{1}}{\partial \theta_{1}} \delta \theta_{1}+\sum_{j=1}^{q} \frac{\partial \mathbf{r}_{1}}{\partial \xi_{j}} \delta \xi_{j}\right) \cdot \mathbf{n}_{1} \\
& =\sum_{j=1}^{q}\left(\frac{\partial \mathbf{r}_{1} \cdot \mathbf{n}_{1}}{\partial \xi_{j}}\right) \delta \xi_{j} .
\end{aligned}
$$

According to (14), the change of the tooth surface geometry represented by the grid points to the change of $\xi_{j}$ can be determined by

$$
\delta^{(i)}=\delta \mathbf{r}_{1}^{(i)} \cdot \mathbf{n}_{1}=\sum_{j=1}^{q}\left(\frac{\partial \mathbf{r}_{1} \cdot \mathbf{n}_{1}}{\partial \xi_{j}}\right) \delta \xi_{j} .
$$

In order to investigate the response of tooth flank form geometry to the small change of the $\xi_{j}$ in terms of $\delta \xi_{j}$, each coefficient in (3) is independently changed and the corresponding normal deviations $\delta^{(i)}$ of the surface points are obtained. The normal deviations at the topographical grid points of both tooth flanks may then be represented in matrix form:

$$
\begin{gathered}
\left\{\begin{array}{c}
\delta^{(1)} \\
\vdots \\
\vdots \\
\delta^{(p)}
\end{array}\right\}=\left[\begin{array}{cccc}
\frac{\partial r_{1}^{(1)}}{\partial \xi_{1}} & \ldots & \ldots & \frac{\partial r_{1}^{(1)}}{\partial \xi_{q}} \\
\vdots & \ddots & & \vdots \\
\vdots & & \ddots & \vdots \\
\frac{\partial r_{1}^{(p)}}{\partial \xi_{1}} & \ldots & \ldots & \frac{\partial r_{1}^{(p)}}{\partial \xi_{q}}
\end{array}\right]\left\{\begin{array}{c}
\delta \xi_{1} \\
\vdots \\
\vdots \\
\delta \xi_{q}
\end{array}\right\} \\
\left\{\delta^{(i)}\right\}=\left[S_{i j}\right]\left\{\delta \xi_{j}\right\} \quad(i=1,2, \ldots, p ; j=1,2, \ldots, q),
\end{gathered}
$$

where $\left\{\delta^{(i)}\right\}$ represents the normal surface errors of the $p$ grid points, $\left[S_{i j}\right]$ is the sensitivity matrix with respect to the polynomial coefficients of the motion function, and $\left\{\delta \xi_{j}\right\}$ represents the small amount of corrections to the polynomial coefficients. The corrections can be approximated using linear regression technique:

$$
\left\{\delta \xi_{j}\right\}=\left(\left[S_{i j}\right]^{T}\left[S_{i j}\right]\right)^{-1}\left[S_{i j}\right]^{T}\left\{\delta^{(i)}\right\} .
$$

Since the sensitivity matrix is ill-conditioned and in most cases nearly singular, in order to obtain a converged solution we use singular value decomposition method to calculate the corrections to the polynomial coefficients of motion function that will avoid divergence. 


\section{Closed-Loop Feedback Correction Process}

A closed-loop correction process has been developed based on hardware and software system of gear form grinding machine, which automatically calculates machine settings and profile of the wheel and generates the grinding process data. To improve tooth precision, increase flank modification flexibility, and satisfy the design demand of large-size gears, we propose a closed-loop correction method like that used in the manufacture of spiral bevel and hypoid gears or cycloidal gears, which has become well developed over the last decade. Figure 6 shows the algorithm of this method.

This method requires the following steps: (1) calculate flank coordinates machine parameters and the wheel profile using gear parameters and machine constants; (2) the work gear is ground and then measured using on-machine measurement, and then the measured data is sent back to the numerical control system of gear form grinding machine; (3) construct the sensitivity matrix through calculating corrective motion coefficients of the machine settings based on the measured flank form errors; (4) a corrective machining is conducted on the form grinding machine, and then the corrected work gear is measured using on-machine measurement again. The closed-loop feedback correction process could be conducted for several iterations between steps (2) and (4) until a work gear with satisfactory tooth flank form accuracy is obtained.

\section{Numerical Example}

A helical gear drive whose design parameters are given in Table 2 is used as a work gear to illustrate the developed method. Some parameters for the wheel data, the machine settings determined, and the crowning coefficient of topological modified tooth flank are listed in Table 2.

In the numerical example after grinding and measuring using on-machine measurement, the sensitivity matrix $\left[S_{i j}\right]$ is obtained using the normal flank deviations of 90 grid points ( $5 \times 9$ topographic points, both flank sides) which are caused by modifying 35 coefficients ( 5 axes $\times 7$ coefficients) one by one through adding a small amount (0.1). As Figure 7 illustrates, in the zero-degree coefficients, all axes influence the flank sensitivity except axis $Z$ and axis $C$.

Figure 8 shows the flank sensitivity topographies of the first-degree coefficients. $Y$ and $C$ axes have greater influence on sensitivity. From Figures 7 and 8, we notice that the higher-order coefficient changes modify both sides of tooth surfaces at the same time. Sensitivities of other higher-order coefficients behave in a similar manner and are not listed in this paper.

The actual flank topographic errors of tooth flank made by the form grinding process can be measured using an on-machine measurement device as shown in Figure 5. In this numerical example, the original flank topographic errors $\left\{\delta^{(i)}\right\}$ are shown in Figure 9. The sum of squared errors of the p-grid points (90 points) is $4683 \mu \mathrm{m}^{2}$. Then we assume the sum of squared errors of topographic points is $2200 \mu \mathrm{m}^{2}$ as a target value and use the least squares method to

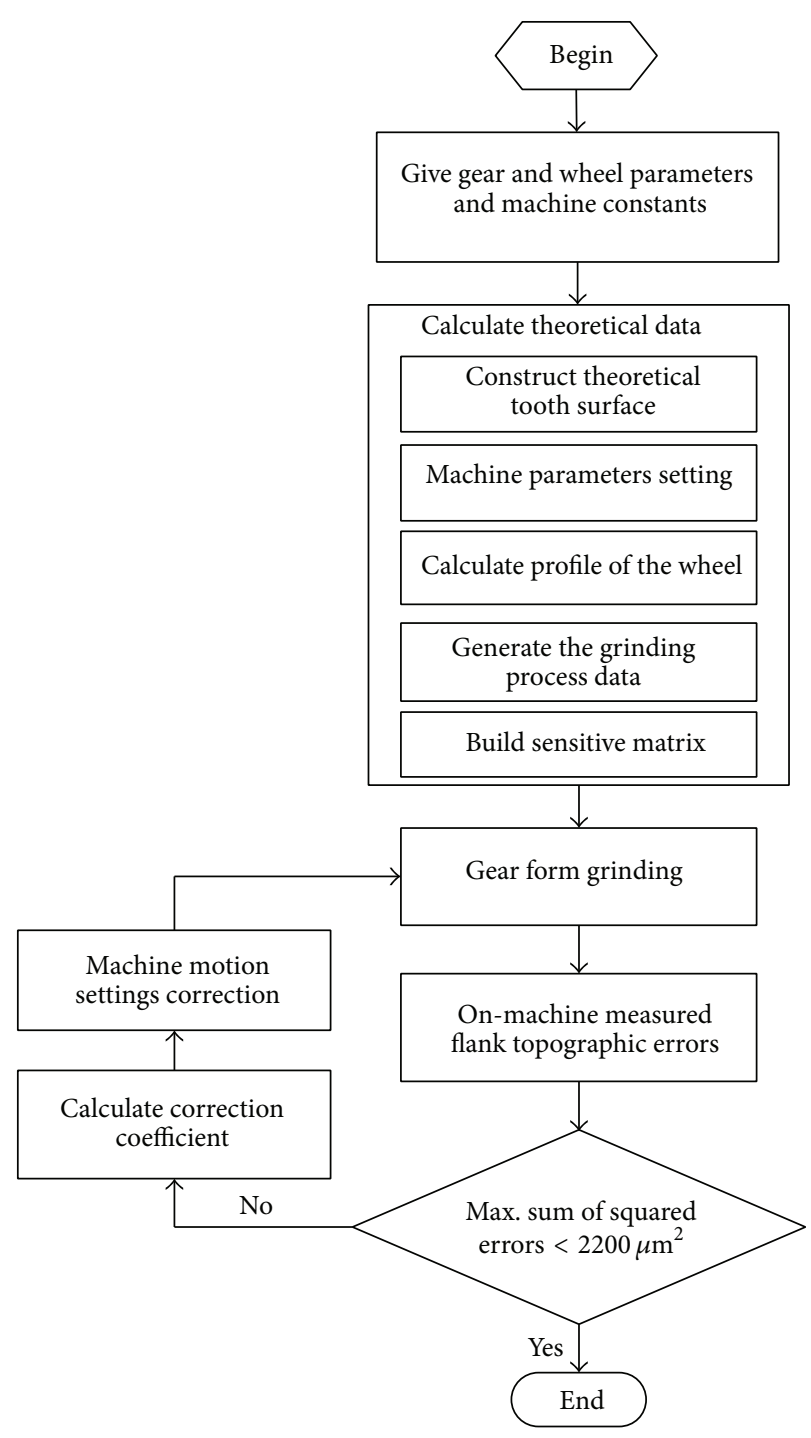

Figure 6: Flow chart for the closed-loop flank correction method for helical gears.

construct the sensitivity matrix $\left[S_{i j}\right]$. Substituting the given flank topographic errors $\left\{\delta^{(i)}\right\}$ and the sensitivity matrix $\left[S_{i j}\right]$ into (17), the corrections $\left\{\delta \xi_{j}\right\}$ to the polynomial coefficients of machine motions can be calculated.

Figure 10 shows the error surfaces after closed-loop feedback correction are selected for the correction. The sum of squared errors is reduced to $1348 \mu \mathrm{m}^{2}$. The original surface errors have been significantly reduced after closed-loop correction, so the proposed correction method is effective in gear form grinding.

\section{Conclusions}

This paper proposes a new method of tooth flank error correction utilizing closed-loop feedback correction on the gear grinding machine for topographic modification of helical gears. Crowned areas are smoothly connected to the 


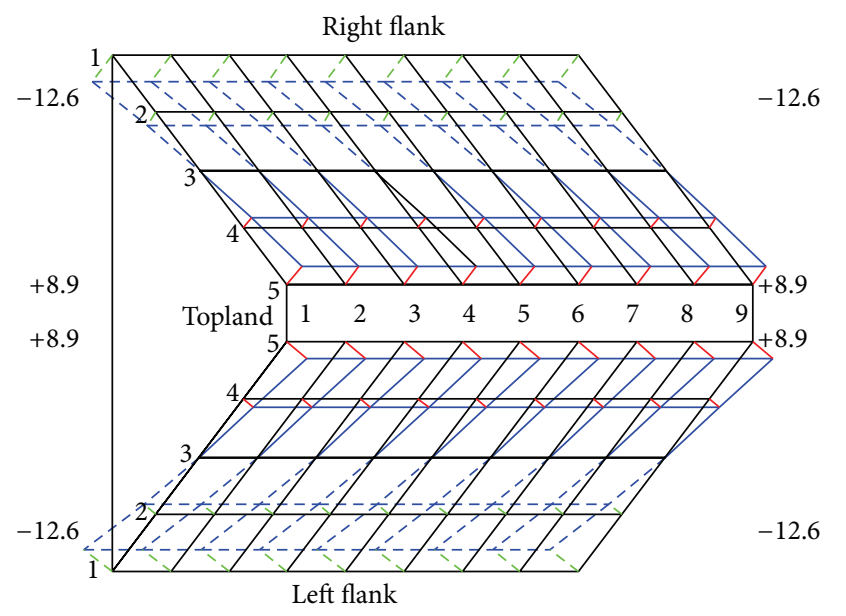

(a) $C_{x 0}+0.1$
Right flank

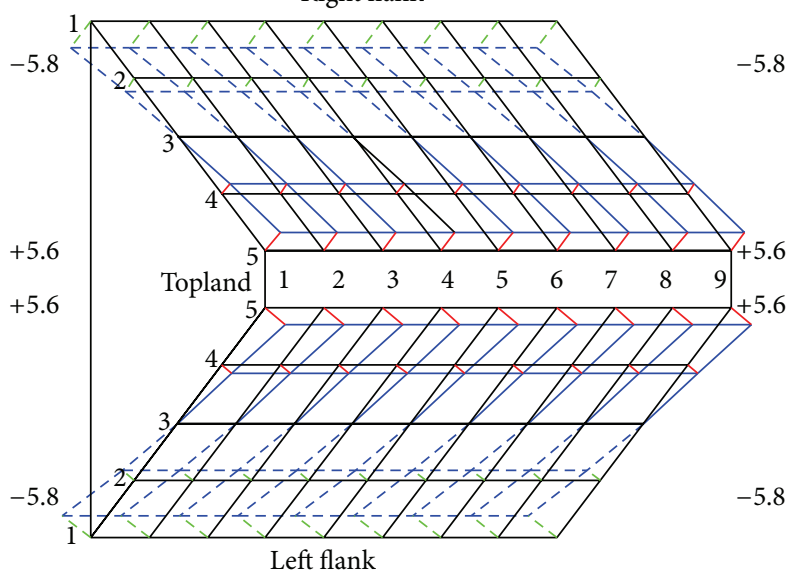

(b) $C_{y 0}+0.1$

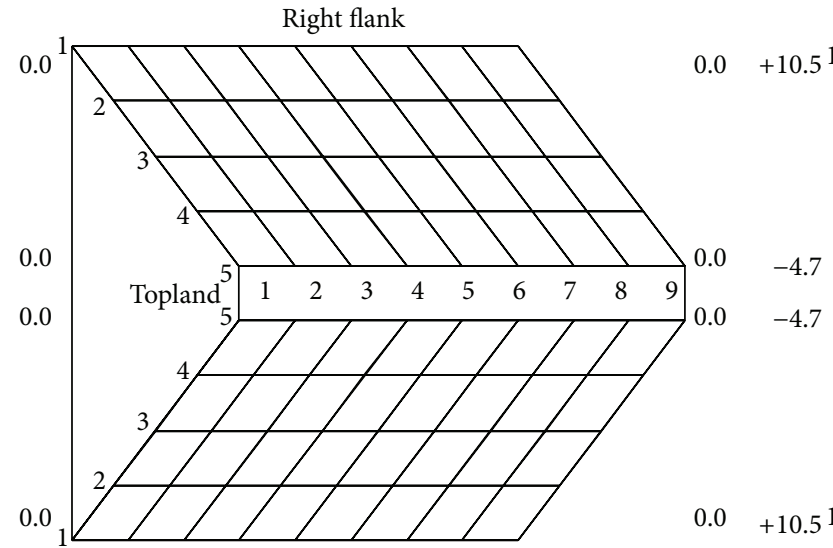

Left flank

(c) $C_{z 0}+0.1$
Right flank

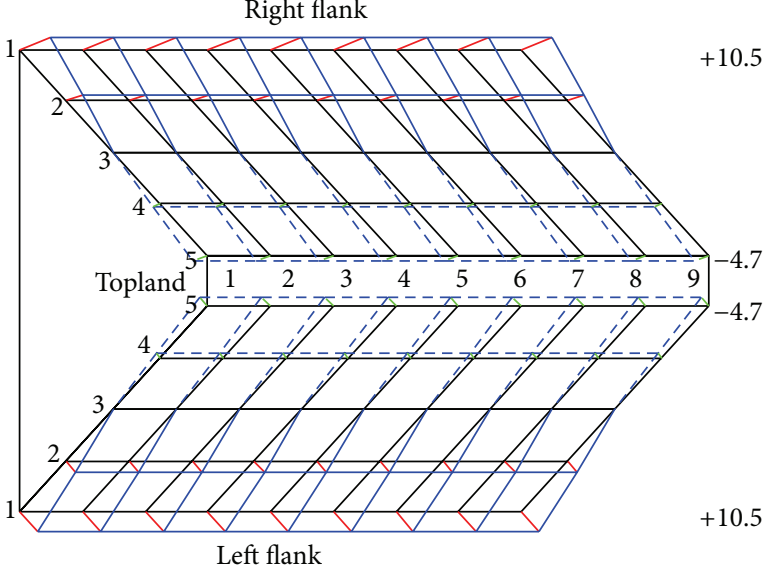

(d) $\varphi_{a 0}+0.1$

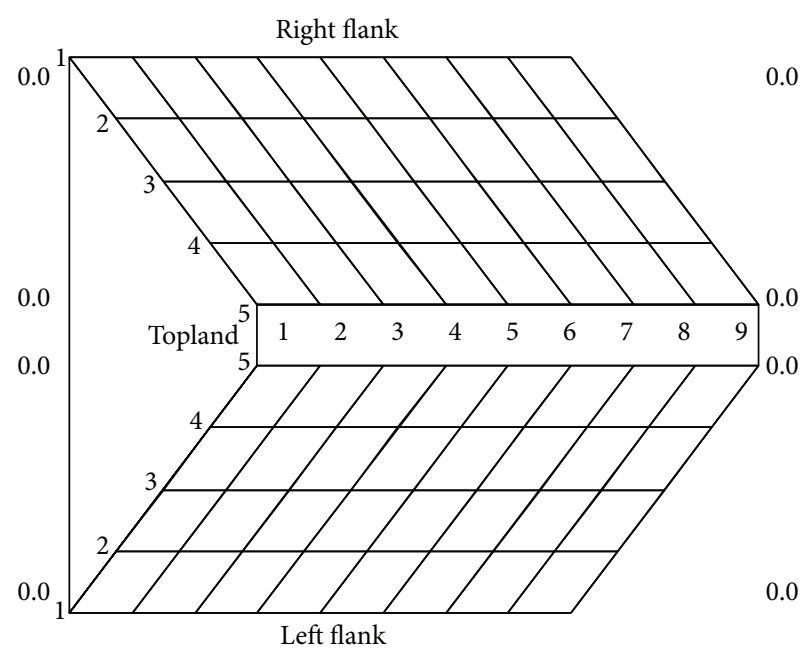

(e) $\varphi_{c 0}+0.1$

FIGURE 7: Flank sensitivity topographies corresponding to the zero-degree polynomial coefficients for axes motion (unit: $\mu \mathrm{m}$ ). 


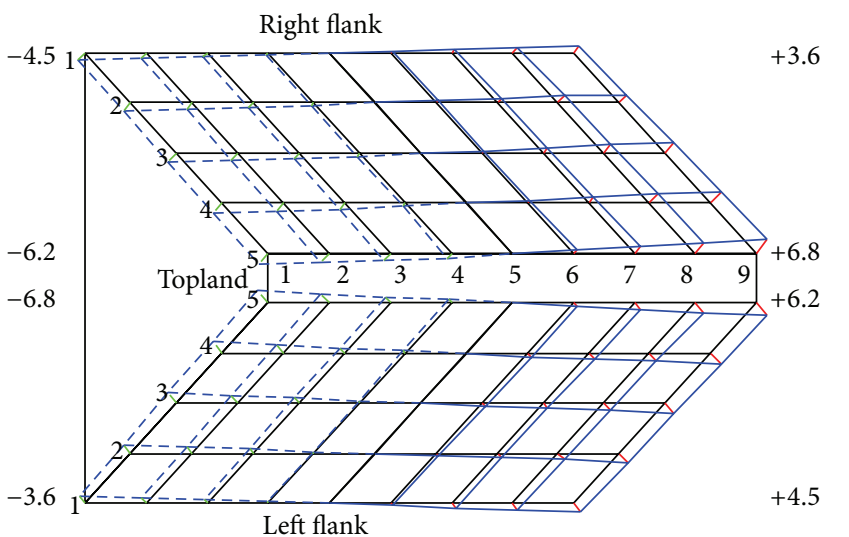

(a) $C_{x 1}+0.1$

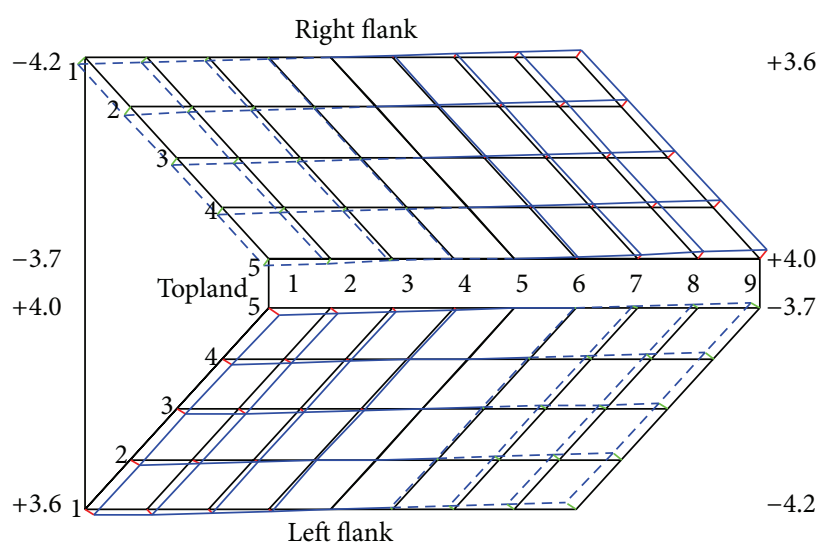

(c) $C_{z 1}+0.1$

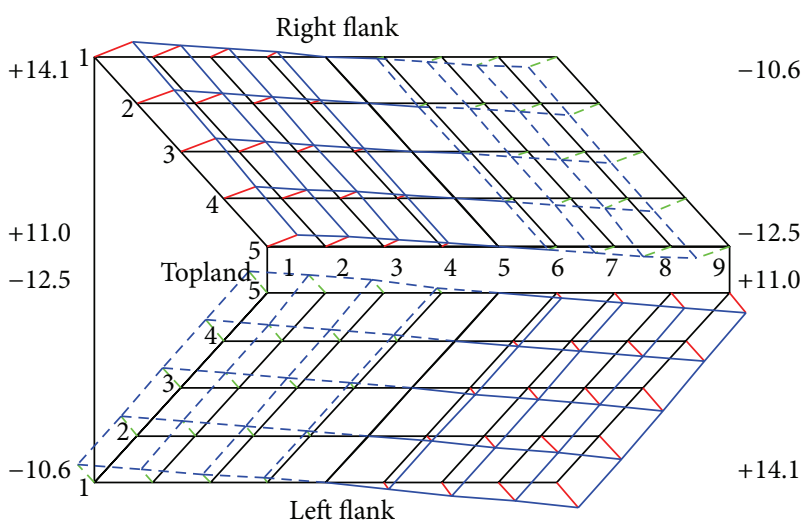

(b) $C_{y 1}+0.1$

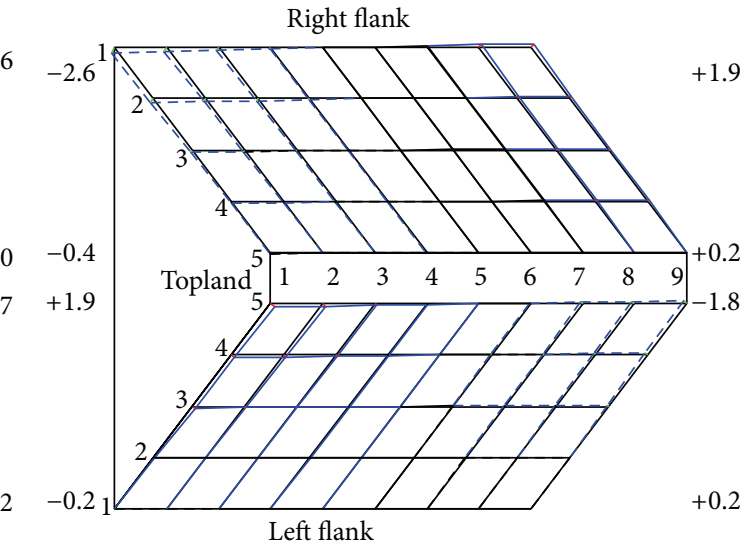

(d) $\varphi_{a 1}+0.1$

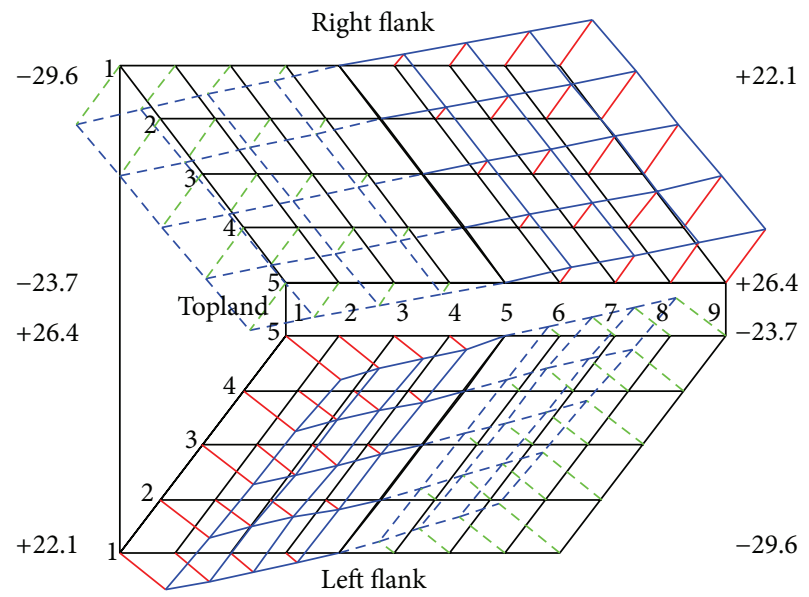

(e) $\varphi_{c 1}+0.1$

FIGURE 8: Flank sensitivity topographies corresponding to the first-degree polynomial coefficients for axes motion (unit: $\mu \mathrm{m}$ ).

involute area and this is achieved by changing the profile and controlling motions of a grinding wheel applied for gear form grinding. The sensitivity of the changes of tooth flank form geometry to the changes of $\mathrm{CNC}$ gear form grinding machine motion coefficients is established. The corrective motion coefficients are obtained through an optimization process with the target of minimization of squared errors of topographic points. As the numerical examples show, closed-loop correction method can improve tooth quality. An additional advantage of the approach is to provide the user with valuable information about the grinding machine and machining capacity. 
TABLE 2: Design parameters for a modified gear drive.

\begin{tabular}{|c|c|c|c|c|}
\hline \multicolumn{3}{|l|}{ Items } & Pinion & Gear \\
\hline \multicolumn{5}{|c|}{ (A) Gear data } \\
\hline Teeth number & $z$ & - & 23 & 26 \\
\hline Normal module & $m_{n}$ & $\mathrm{~mm}$ & 5 & 5 \\
\hline Pressure angle & $\alpha_{n}$ & deg & 20 & 20 \\
\hline Helix angle & $\beta$ & deg & 11.478 & 11.478 \\
\hline Face width & $b$ & $\mathrm{~mm}$ & 53 & 53 \\
\hline Coefficient of profile shift & $x_{n}$ & - & 0.032 & -0.032 \\
\hline
\end{tabular}

(B) Wheel data

\begin{tabular}{llll} 
Outer diameter & $d_{w}$ & $\mathrm{~mm}$ & 300.000 \\
Width & $w_{w}$ & $\mathrm{~mm}$ & 60.000 \\
\hline
\end{tabular}

(C) Machine settings

\begin{tabular}{lllc} 
Setting angle of the wheel & $\gamma_{m}$ & $\mathrm{deg}$ & 11.478 \\
Center distance & $E_{t}$ & $\mathrm{~mm}$ & 210.077 \\
Axial movement & $L_{t}$ & $\mathrm{~mm}$ & $326.647 \varphi_{1}$ \\
\hline
\end{tabular}

(D) Crowning coefficient

\begin{tabular}{lcccc} 
Top profile crowning & $a_{m p(c f)}$ & $1 / \mathrm{mm}$ & 0 & 0.001 \\
Bottom profile crowning & $a_{m p(d e)}$ & $1 / \mathrm{mm}$ & 0 & 0.0005 \\
Top limit angle & $u_{c}$ & $\mathrm{rad}$ & 0 & 0.511 \\
Bottom limit angle & $u_{d}$ & $\mathrm{rad}$ & 0 & 0.145 \\
Front longitudinal crowning & $a_{m l(h a)}$ & $1 / \mathrm{mm}$ & 0 & 0.0008 \\
Back longitudinal crowning & $a_{m l(b j)}$ & $1 / \mathrm{mm}$ & 0 & 0.0008 \\
Front limit & $\theta_{a}$ & $\mathrm{rad}$ & 0 & 0.024 \\
Back limit & $\theta_{b}$ & $\mathrm{rad}$ & 0 & 0.138 \\
\hline
\end{tabular}

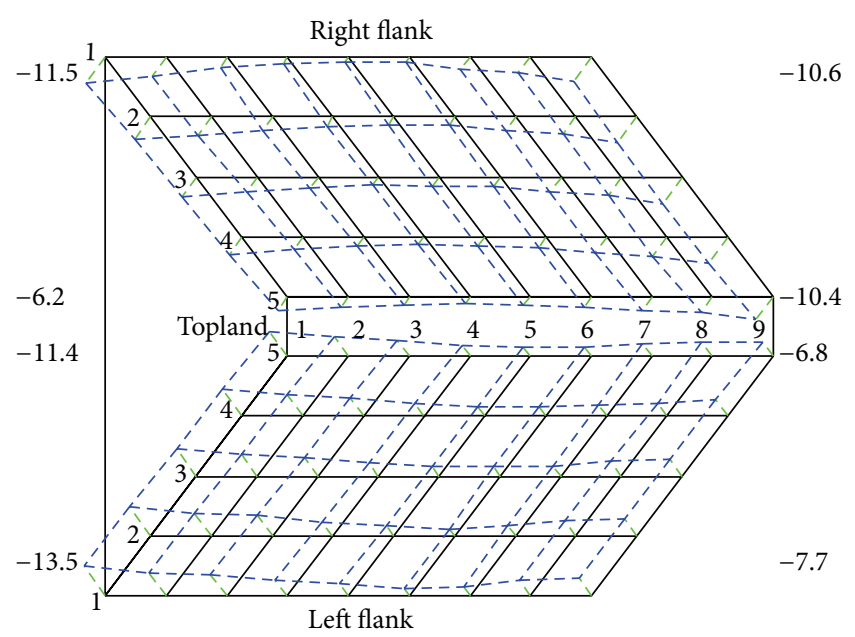

FIGURE 9: Original flank topographic error surfaces before correction (unit: $\mu \mathrm{m}$ ).

\section{Conflict of Interests}

The authors declare that there is no conflict of interests regarding the publication of this paper.

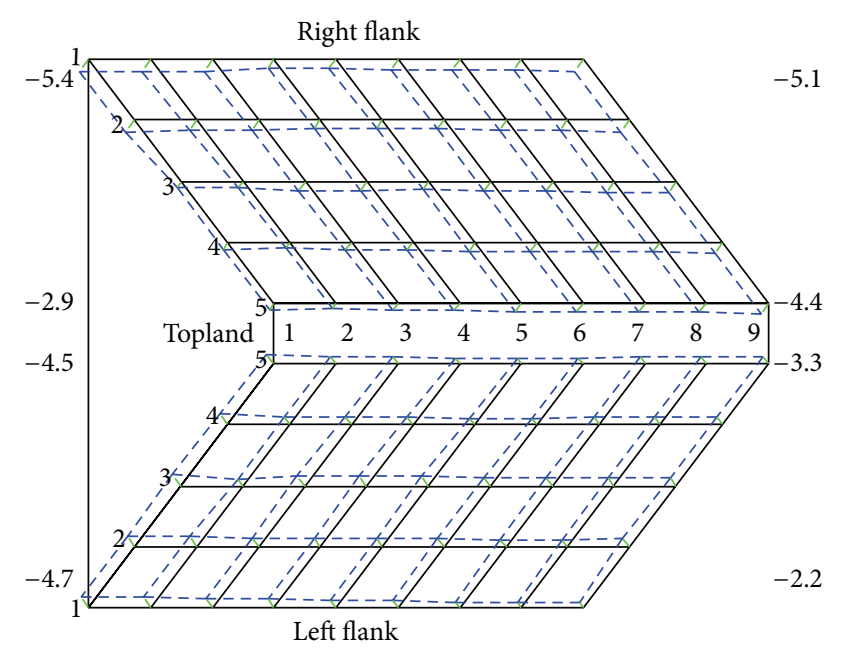

FIgURE 10: Error surfaces after closed-loop feedback correction (unit: $\mu \mathrm{m}$ ).

\section{Acknowledgments}

The authors are grateful to the National Natural Science Foundation of China for its financial support. Part of this work was performed under Contracts nos. 51375144 and 51405135 .

\section{References}

[1] S. Oh, J. Kang, I. Lee, and S. Lyu, "A study on modeling and optimization of tooth microgeometry for a helical gear pair," International Journal of Precision Engineering and Manufacturing, vol. 14, no. 3, pp. 423-427, 2013.

[2] J. Argyris, M. De Donno, and F. L. Litvin, “Computer program in visual basic language for simulation of meshing and contact of gear drives and its application for design of worm gear drive," Computer Methods in Applied Mechanics and Engineering, vol. 189, no. 2, pp. 595-612, 2000.

[3] F. L. Litvin and A. Fuentes, Gear Geometry and Applied Theory, chapters 17 and 28, Cambridge University Press, New York, NY, USA, 2nd edition, 2004.

[4] H.-Y. You, P.-Q. Ye, J.-S. Wang, and X.-Y. Deng, "Design and application of CBN shape grinding wheel for gears," International Journal of Machine Tools and Manufacture, vol. 43, no. 12, pp. 1269-1277, 2003.

[5] S. P. Fang, Y. S. Liu, H. Y. Wang, T. Taguchi, and R. Takeda, "Research on the compensation method for the measurement error of cycloidal gear tooth flank," International Journal of Precision Engineering and Manufacturing, vol. 15, no. 10, pp. 2065-2069, 2014.

[6] Y.-P. Shih and S.-D. Chen, "Free-form flank correction in helical gear grinding using a five-axis computer numerical control gear profile grinding machine," Journal of Manufacturing Science and Engineering, vol. 134, no. 4, Article ID 41006, 2012.

[7] Q. Fan, R. S. DaFoe, and J. W. Swanger, "Higher-order tooth flank form error correction for face-milled spiral bevel and hypoid gears," Journal of Mechanical Design, vol. 130, no. 7, Article ID 072601, 2008.

[8] Q. Fan and R. S. DaFoe, "Gleason expert manufacturing system (GEMS) opens a new era for digitized manufacturing of spiral 
bevel and hypoid gears," World Manufacturing Engineering \& Market, vol. 79, no. 4, pp. 87-93, 2005.

[9] H. Yoshino and K. Ikeno, "Error compensation for form grinding of gears," Transactions of the Japan Society of Mechanical Engineers, Part C, vol. 57, no. 543, pp. 3652-3655, 1991.

[10] F. L. Litvin, N. X. Chen, J. Lu, and R. F. Handschuh, "Computerized design and generation of low-noise helical gears with modified surface topology," Transactions of the ASME, Journal of Mechanical Design, vol. 117, no. 2, pp. 254-261, 1995.

[11] F. L. Litvin, D. Vecchiato, K. Yukishima, A. Fuentes, I. GonzalezPerez, and K. Hayasaka, "Reduction of noise of loaded and unloaded misaligned gear drives," Computer Methods in Applied Mechanics and Engineering, vol. 195, no. 41-43, pp. 5523-5536, 2006.

[12] Y. Kobayashi, N. Nishida, Y. Ougiya, and H. Nagata, "Tooth trace modification processing of helix gear by form grinding method," Transactions of the Japan Society of Mechanical Engineers, Part C, vol. 61, no. 590, pp. 4088-4093, 1995.

[13] Y. Kobayashi, N. Nishida, Y. Ougiya, and H. Nagata, "Estimation of grinding wheel setting error in helical gear processing by form grinding," Transactions of the Japan Society of Mechanical Engineers, Part C, vol. 63, no. 612, pp. 2852-2858, 1997.

[14] T. J. Krenzer, Computer Aided Corrective Machine Settings for Manufacturing Bevel and Hypoid Gear Sets, Fall Technical Meeting Series, American Gear Manufacturers Association, Washington, DC, USA, 1984.

[15] H. Zhang, X.-D. Huang, H. Yuan, C.-G. Fang, and E.-K. Guo, "Compensation for tooth profile deviations of gear profile grinding with grinding wheel position," Computer Integrated Manufacturing Systems, vol. 19, no. 6, pp. 1288-1295, 2013.

[16] C.-K. Lee, "Manufacturing process for a cylindrical crown gear drive with a controllable fourth order polynomial function of transmission error," Journal of Materials Processing Technology, vol. 209, no. 1, pp. 3-13, 2009.

[17] C.-K. Lee and C.-K. Chen, "Mathematical models, meshing analysis and transmission design for a robust cylindrical gear set generated by two blade-discs with parabolic cutting edges," Proceedings of the Institution of Mechanical Engineers Part C, vol. 218, no. 12, pp. 1539-1554, 2004.

[18] C. Gorla and F. Rosa, "Form grinding of helical gears: effects of disk shaped tools plunging," in Proceedings of the ASME Design Engineering Technical Conferences and Computers and Information in Engineering Conference, vol. 4, pp. 731-739, September 2003.

[19] A. Artoni, M. Gabiccini, and M. Kolivand, "Ease-off based compensation of tooth surface deviations for spiral bevel and hypoid gears: only the pinion needs corrections," Mechanism and Machine Theory, vol. 61, pp. 84-101, 2013.

[20] V. Simon, "Head-cutter for optimal tooth modifications in spiral bevel gears," Mechanism and Machine Theory, vol. 44, no. 7, pp. 1420-1435, 2009.

[21] M. Kolivand and A. Kahraman, "A load distribution model for hypoid gears using ease-off topography and shell theory," Mechanism and Machine Theory, vol. 44, no. 10, pp. 1848-1865, 2009.

[22] H. L. Wang, X. Z. Deng, K. Xu, J. J. Yang, and J. X. Su, "Load tooth contact analysis (LTCA) of helical gears using topographic modification and installation errors," Journal of Northwestern Polytechnical University, vol. 32, no. 5, pp. 781-786, 2014. 


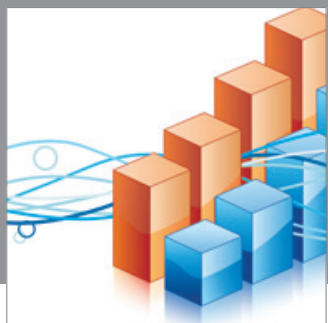

Advances in

Operations Research

mansans

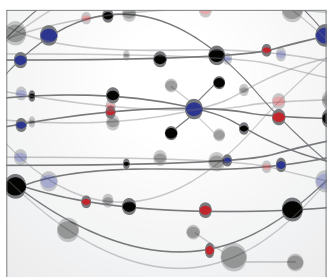

The Scientific World Journal
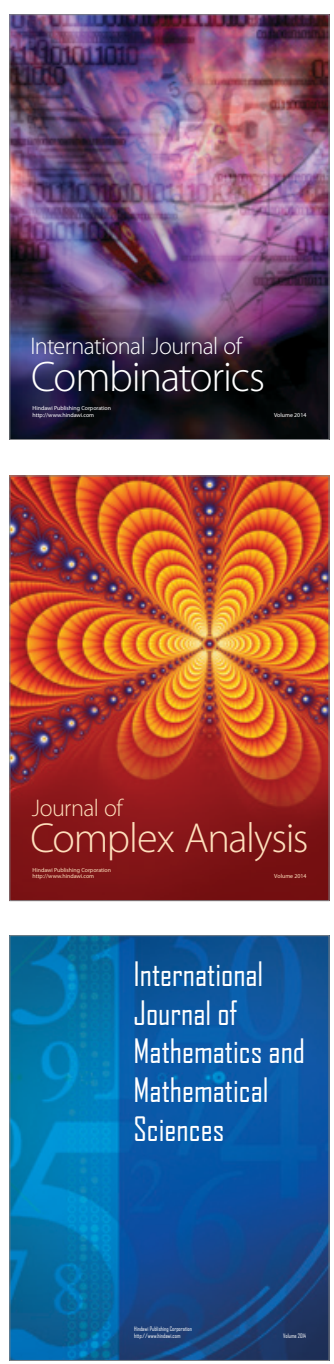
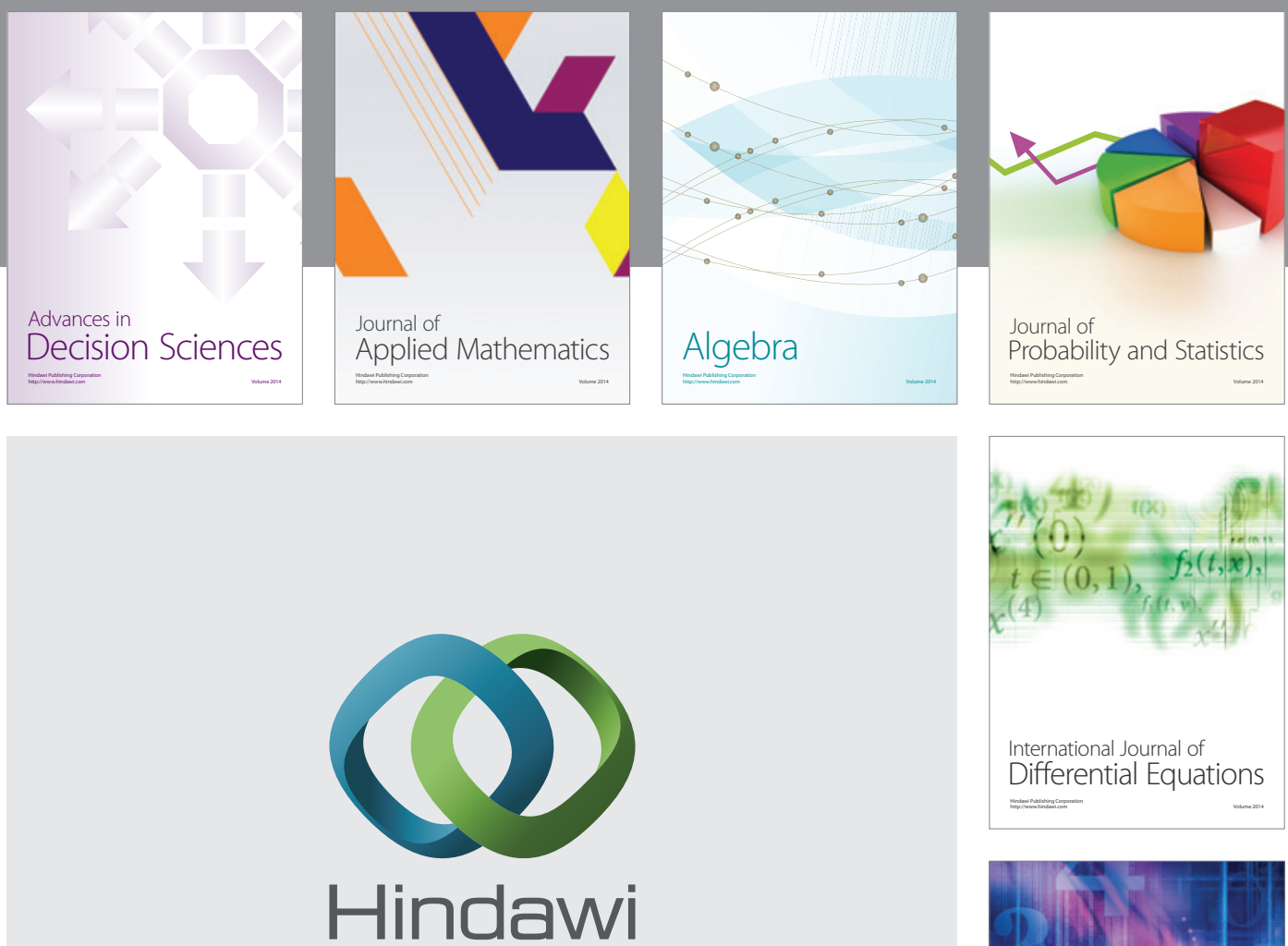

Submit your manuscripts at http://www.hindawi.com
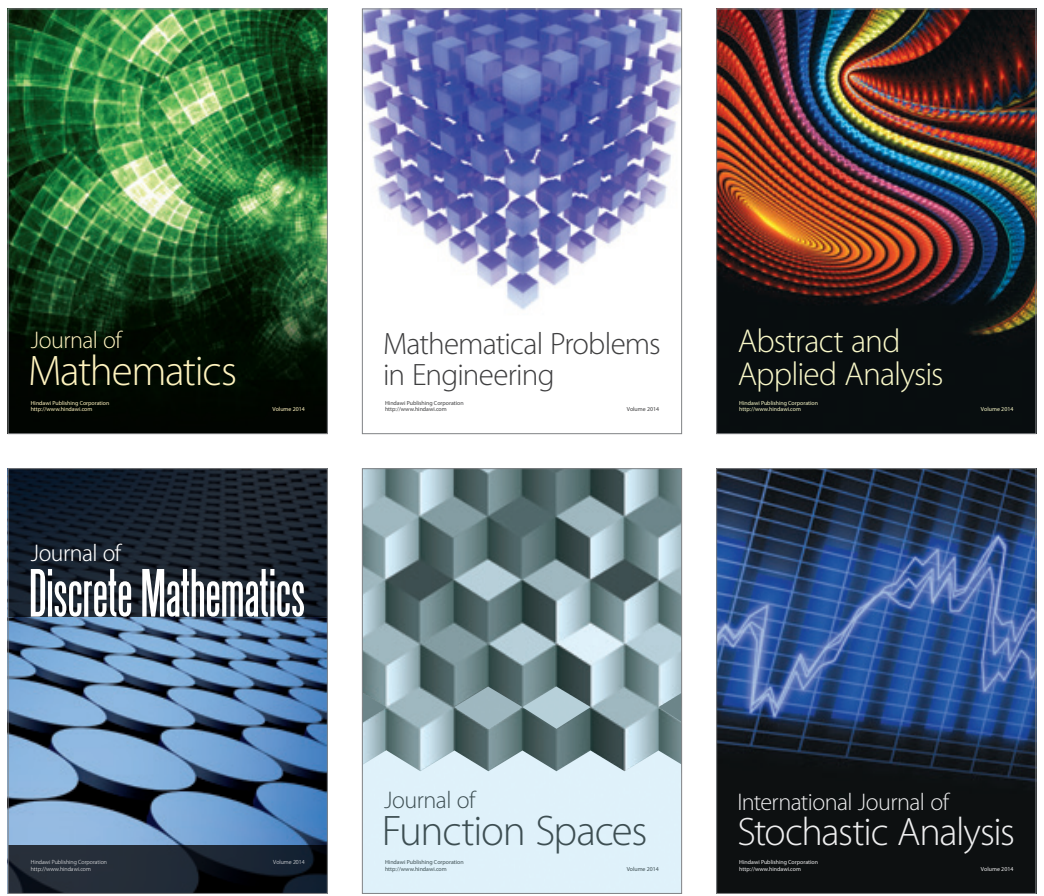

Journal of

Function Spaces

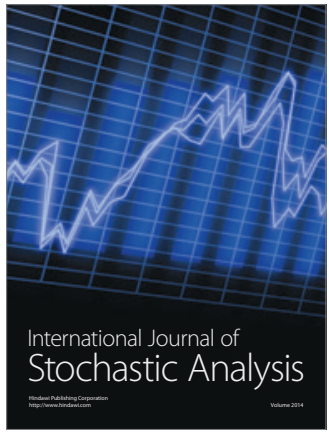

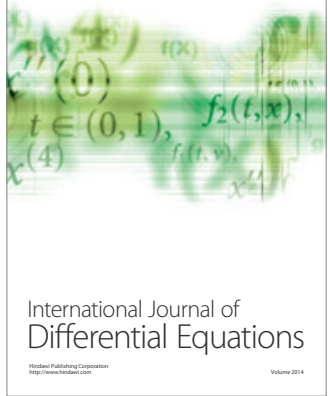
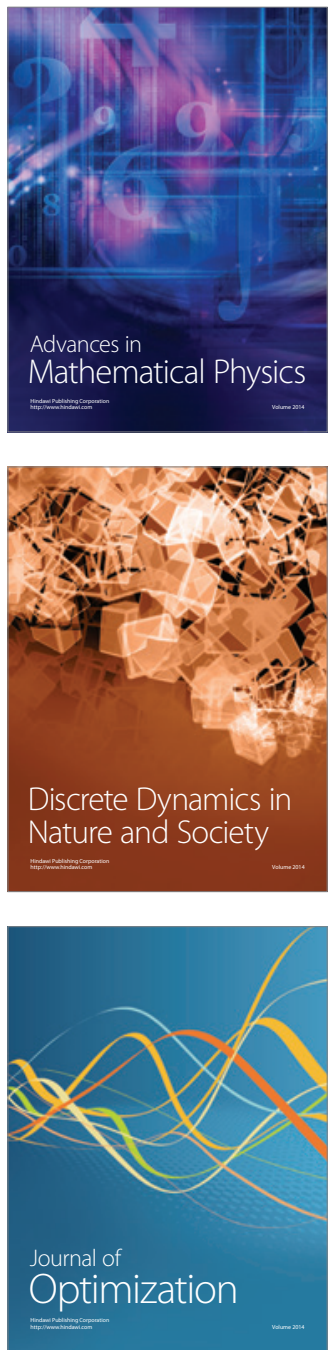